\title{
Educational Philosophy and Theory
}

\section{Corrupted temporalities, 'cultures of speed', and the possibility of collegiality}

\section{Ian James Kidd}

To cite this article: Ian James Kidd (2021): Corrupted temporalities, 'cultures of speed', and the possibility of collegiality, Educational Philosophy and Theory, DOI: 10.1080/00131857.2021.2017883

To link to this article: https://doi.org/10.1080/00131857.2021.2017883 (c) 2021 The Author(s). Published by Informa
UK Limited, trading as Taylor \& Francis Group.

曲 Published online: 20 Dec 2021.

Submit your article to this journal $₫$

III Article views: 47

Q View related articles ¿

View Crossmark data 


\title{
Corrupted temporalities, 'cultures of speed', and the possibility of collegiality
}

\author{
lan James Kidd
}

Department of Philosophy, University of Nottingham, Nottingham, NG72QL, United Kingdom of Great Britain and Northern Ireland

\begin{abstract}
This paper describes a neglected aspect of the critique of academic 'cultures of speed' offered by Maggie Berg and Barbara Seeler in The Slow Professor. I argue internalisation of the values and imperatives of cultures of speed can encourage the erosion of a range of academic virtues while also facilitating the development of a range of academic vices. I focus on the ways that an internalised 'psychology of speed' erodes our capacity to exercise the virtues of intellectual beneficence excellences of character which advance the intellectual needs of others by radically distorting our experience of time.
\end{abstract}

\section{ARTICLE HISTORY}

Received 17 August 2021 Revised 22 November 2021

Accepted 26 November 2021

\section{KEYWORDS}

Academia; corruption; speed; time; virtue; vice

\section{Introduction}

There is a vigorous contemporary literature devoted to critical discourses of higher education, including scholarly historical and sociological studies, therapeutic 'self-help' for academics, and political and polemical exercises devoted to challenging or defending contemporary ideas about the nature and value of universities. One striking aspect of this discourse is a consistent use of a vocabulary of corruption to characterise the changes to higher education and their effects on the character of the academics who teach and research within it.

Consider some examples of this language of corruption from some of the best-known participants in those critical discourses. First, Martha Nussbaum has regularly warned that contemporary tendencies to rote learning, mindless memorisation, and curricular myopia are tending to 'corrupt the mission of humanistic scholarship' (Nussbaum, 2010, p. 130). Second, Collini warns that instrumentalism and philistinism are driving the 'corruption' of scholars' venerable role as the 'custodians' of our 'complex intellectual inheritance' (Collini, 2012, p. 199). Third, Michael Sandel condemns the relentless imposition of market-based thinking onto higher education on the grounds that its consequent culture of aggressive performativity, assessment, and testing 'erode, or crowd out, or corrupt' what, for an educator, should really matter - namely, a 'love of reading', learning, and education for its own sake (Sandel, 2012, p. 61). Many other concerns about higher education expressed in a language of corruption could be cited, always in tones of concern and condemnation.

CONTACT lan James Kidd ian.kidd@nottingham.ac.uk D Department of Philosophy, University of Nottingham, Nottingham, NG72QL, United Kingdom of Great Britain and Northern Ireland. 
A rhetoric of corruption is appropriately dramatic, since it still carries its older moral and theological resonances as well as being continuous with contemporary use of the term 'corruption' within critical political discourse. But resonances are not definitions: we should want a better grasp of what is meant when talking about modern developments in the organisation and direction of higher education as being corrupting. Unfortunately, those who deploy the term tend not to define it. This is doubly problematic. First, there are many options and not all of them will be appropriate or intended by the critic - think, for instance, of senses of corruption like selling university places or accepting funding from Big Tobacco. Second, if we are without a clear definition, then we are risk of misdiagnosing the nature of the concerns and so of failing to grasp what was really intended by the critic. Getting the concept clear will help us make better sense of the claims and criticisms reflected in that talk of corruption.

The closest attempt at definition, to my knowledge, is Sandel's remark that to corrupt something is to evaluate it according to lower standards than are appropriate to it, like when one starts to think of a close personal friend in narrowly instrumental terms (Sandel, 2012, p. 34). Here, education becomes corrupted when it is made to server lower, more ignoble aims than those appropriate to it - aims like profit, for instance, or promotion of nativist nationalist sentiment. Sandel's definition recalls an earlier contribution to critical discourses of higher education: a once-famous paper by Michael Oakeshott condemning 'the frustration of education'. Tucked away in its opening pages is a proposal that to corrupt a thing means to treat it in ways that tend to 'deprive it of its character' (Oakeshott, 1971, p. 57). Oakeshott presumably meant the positive features or qualities of character of a person or thing, whose loss would be a cause for frustration or lamentation. In the case of people, of course, positive qualities are virtues and other excellences of character, like courage and fairmindedness and truthfulness. Vices are the negative character traits, like closedmindedness, selfishness, and wilful ignorance. It is this set of connections between character, corruption, and higher education that I want to explore in this paper.

Specifically, my claim is that there is a specific sense of corruption which refers to the gradual deterioration or destruction of the moral and intellectual character of human beings, a sense of course consistent with other definitions not focused on character. I have elsewhere offered fairly complex accounts of this character-based conception of corruption and philosophical vice theory that grounds it (see Kidd, 2020, 2022). I think many higher education discourses express, albeit often indirectly, worries about the effects of commercialisation, marketisation, and other bugbears on the moral and intellectual character of academics. Such worries can be stated in a language of corruption, the negative counterpart to edification, the idea that education ought to facilitate the cultivation and exercise of virtues and excellences of character. Not everyone agrees with edification, of course, and my criticisms of corruption does not require acceptance of edificationist conceptions of education (for defences, though, see Arthur et al., 2016 and Baehr, 2015). You do not need to think education ought to promote virtue and wisdom to worry about promotion of arrogance, dogmatism, and other failings of epistemic character. Of course, one will be more inclined to worry if one is signed up to some form of edificationism.

A small literature exists devoted to character-based criticisms of higher education of a sort continuous with what I am proposing. Usually these come, unsurprisingly, from those with a background in virtue ethics; oddly, there is such a thing as virtue ethics, devoted to the sunnier side of moral character, but little by way of a vice ethics, devoted to the many failings of moral character (some exceptions are Shklar, 1984 and Taylor, 2006). Two critics are Heather Battaly and David E. Cooper. Each offer criticisms of higher educational culture and practices that focus on their tendencies to promote vices or erode virtues (Battaly, 2013; Cooper, 2008). What they describe are complex and institutionally scaffolded processes of corruption that act on character in different ways - by, for instance, introducing incentives to dishonest conduct or creating working conditions that militate against fairmindedness and other epistemic virtues. For these reasons, we should conceive of character corruption - as I will call it - in terms of sustained, dynamic processes whereby a corruptee interacts, 
albeit often with critical resistance, with a variety of corruptors, the result of which is often a deterioration of their virtues and the facilitation of their vices (see, for a fuller account, Kidd, 2019).

I want to use this character-based conception of corruption to think through the claims and concerns raised in one recent, influential contribution to those critical higher educational discourse. This is the Canadian literary scholars Maggie Berg and Barbara Seeler's book The Slow Professor and its castigation of what they call the 'culture of speed in the academy'. Much of their book is a self-confessed polemic against various awful features of modern higher education articulable in using the conceptual metaphors of 'speed', 'slowness' and 'acceleration' which, they argue, offer deep insights into the psychologies of teachers, researchers, and administrators and the culture and rhythms of modern higher education. If Berg and Seeber are right, cultures of speed are increasingly prevalent in modern cultures, but their focus, like mine, are their manifestations in academia and higher education.

I sympathise with much of Berg and Seeler's critique of cultures of speed and its very compelling account of the harms done to teaching, scholarship, and staff and student mental health. One latent aspect of that critique that needs drawing out, though, is a specific form of harm that can be drawn out using a character-based conception of corruption. Subjection to and internalisation of the imperatives of cultures of speed are corrupting insofar as they are, I hope to show, liable to put pressure on certain clusters of academic virtues, while the same time fuelling the development of certain clusters of academic vices. If so, then we can add to the critique of cultures of speed the further charge that they are corrupting the character of the practitioners of higher education. In later stages of the paper, I argue that a main way they are corrupting is by distorting our experience of time.

\section{Slowness and speed}

In common use, 'slowness' often has a derogatory sense of limited intelligence, dumbness, or stupidity, usually coupled to connections of 'slothful' and 'sluggish'. Yet as Áine Mahon, notes, this is too narrow. 'Slowness' also has several positive senses, like 'measured', 'moderate', and 'gradual', and 'going slowly' can mean taking one's time to think and act in ways that are attentive and unhurried (Mahon, 2021, p. 3). Slowness, in these senses, has over the last thirty years been developed into a popular social movement and philosophy with its own moral, cultural, and political dimensions. Originating in the early ' $90 \mathrm{~s}$ in the Italian Slow Food movement, 'Slowness' came to mean embracing ways of living devoted to unhurried appreciation, carefulness, and sustainability, qualities integral to what its founder, Carlo Petrini, called 'a new moral imperative' (Petrini, 2004, p. 71). Setting itself against the modern cultures of rapid consumption and production, Slowness developed into a broad moral, cultural, and political movement, with Slow food, Slow science, Slow sex, and more.

The philosophy of Slowness was first articulated by the journalist Carl Honoré in what quickly became a bestselling book, In Praise of Slow. ${ }^{1}$ Speaking in portentous tones, he characterises Fastness as a dangerous and destructive feature of late modern culture with severe physical, emotional, economic, and environmental costs. 'We are all enslaved by speed', trapped by insatiable imperatives to become faster and more productive in ways that beyond a certain point 'strikes at the heart of what it is to be human' (Honoré, 2005, pp. 16-17). Fast is implicated in the wastefulness of fast fashion, rapacious exploitation of nature, the punishing demands and pace of work life and other modern ills. For these reasons, the Slow movement was aligned by Honore with various progressive concerns, from a 'green' concern with protection of nature to defences of worker rights.

The positive aspiration of In Praise of Slowness is to describe strategies of resistance, some personal and private, others collective and grounded in grassroots political activism. An effort to slow down our daily habits, for instance, can involve changing our relationships to food, to 
cultivate appreciation of restfulness and more leisurely rates of activity. Indeed, abandoning the temptation to always be active is also part of the Slow aspiration. Honoré suggests trying to combine happy periods of empty, purposeless time with 'activities that defy acceleration', such as meditation or reading or walking. Unfortunately, since those activities are susceptible to acceleration, what emerges as really essential is the effort to 'cultivate inner Slowness' (Honoré, 2005, p. 274).

Honoré describes these 'inner' dimensions:

Fast and Slow do more than just describe a rate of change. They are shorthand for ways of being, or philosophies of life. Fast is busy, controlling, aggressive, hurried, analytical, stressed, superficial, impatient, active, quantity-over-quality. Slow is the opposite: calm, careful, receptive, still, intuitive, unhurried, patient, reflective, quality-over-quantity. It is about making real and meaningful connections (Honoré, 2005, p. 14)

Crucially, condemnation of 'cultures of speed' is nothing as crude as urging people to simply 'Slow down'. Within the course of life, there are appropriate moments for going Fast and Slow, so what is really needed is what musical theorists call tempo giusto - an intelligent, sensitive capacity to recognise the right speed, something that involves the exercise of a suite of virtues that includes attentiveness, discipline, humility, and restraint. As Honoré explains:

Most of us do not wish to replace the cult of speed with the cult of slowness. Speed can be fun, productive and powerful, and we would be poorer without it. What the world needs, and what the Slow movement offers, is a middle path [...] The secret is balance: instead of doing everything faster, do everything at the right speed. Sometimes fast. Sometimes slow. Sometimes somewhere in between (Honoré, 2005, p. 274)

Staying with the musical analogy, a good performer knows that some pieces should be played slowly, others quickly. In most cases, skilful performance involves one's sensitivity to carefully constructed rhythms of alternating speed and slowness - allegro and largo. Berg and Seeber use musical analogies, too: Slowness means learning how to 'give meaning' to 'periods of rest', and to those 'pauses and periods that may seem unproductive' (Berg \& Seeber, 2016, p. 57).

The point of Honoré's critique is not to condemn Fast and instead to celebrate Slow, since each of those have their proper roles within human life. The metaphor of a rhythm to a life may in a sense be superior, since a good rhythm can accommodate the fast and the slow. In any case, the worry is about the entrenchment of 'cultures of speed' that work to drive the extension of Fast into increasingly more areas of life. What one loses, amid the rush, is that 'inner Slowness' - a cultivated capacity for Slowness, supported by the sorts of virtues cited by Petrini. Under the pressures of a culture of speed, one is at risk of internalising accelerative imperatives that drive us to ever-faster - to do more and be more in a culture that also associates activity and productivity with personal identity and worth. What can happen is that we lose our capacity for those virtues premised on Slow styles of thought, feeling, and action and instead become dominated by accelerative vices, reflecting a failure to evince proper attentiveness, sensitivity, and restraint. Hence Honorés dramatic warning that zeal for Fastness 'strikes at the heart of what it is to be human' (Honoré, 2005, pp. 16-17).

I want to explore this idea that cultures of speed are objectionable because they tend to corrupt the character of individuals who internalise their values and imperatives - what we might call a psychology of speed and acceleration. I think this sort of worry lurks under the surface of Berg and Seeber's critique of cultures of speed, although their account, as it stands, faces two problems. They do not specify the sorts of vices being promoted, nor explain for us the relevant processes of corruption. I therefore try to repair both omissions by arguing that internalisation of the accelerative imperatives of 'cultures of speed' will tends to distort our experiences of time in ways that interfere with our capacity to cultivate and exercise certain virtues of academic collegiality. 


\section{Acceleration and academia}

The Slow Professor is a short, lively, influential polemic against the 'culture of speed' the authors see as increasingly characteristic of modern higher education. Its stated aims are 'to alleviate work stress, preserve humanistic education, and resist the corporate university' (Berg \& Seeber, 2016, p. ix). Crucially, the culture of speed is not simply located in the norms and pace of institutional lie, but also, at a deeper level, in fundamental ways of experiencing academic life and activity - a stance organised around an ethos of speed and productivity of a sort emobodied in those whom Berg and Seeler call 'disciples of speed', those blinkered devotees of the 'cult of speed' (Berg \& Seeber, 2016, p. 60). Along the way, they quote other critics outraged at certain consequences of a culture of speed, including a pair of authors who feel the need to announce that 'we have a right to health' and 'a right to a private life' or another for whom current attacks on universities are 'worse than those under McCarthy' (quoted in Berg and Seeber 2016, pp. 9, 17).

The Slow Professor surveys the various destructive effects of the academic culture of speed on teaching, scholarship, collegiality, educational values, and bodily and mental health. Like Honoré, Berg and Seeber also clarify misconceptions about what Slowness entails. It is, or instance, 'not a counter-cultural retreat from everyday life', nor a form of laziness, of what two authors nicely call 'a slow-motion version of life' (Parkins and Craig quoted in Berg \& Seeber, 2016, p. 11). Slowness means attentiveness, conscientiousness, diligence, preparedness, thoughtfulness, reflectiveness. Moreover, Slowness is not a means to enable more sustainable forms of productivity, just the latest trendy 'self-help' strategy that's really just another way of ensuring the workers carry on business-as-usual. On the contrary, Berg and Seeber insist that Slow should be 'subversive', that enacting Slow principles to academia should be seen as part of a wider effort to foster 'intellectual work, social critique, and engaged citizenship'. An obvious end-goal is for The Slow Professor to start 'a counter-discourse of Slow scholarship, understanding, and ethical engagement' (Berg \& Seeber, 2016, pp. vi, 13-14).

I sympathise with concerns about a culture of speed, although worry that Berg and Seeler undersell their book by calling it as 'a self-help book for academics' (Berg \& Seeber, 2016, p. 13). Its headline concern with mental health is one part of what is really a systematic critique that takes in the historical, economic, and ideological dimensions of the 'culture of speed'. Moreover, the talk of 'self-help' sits alongside vigorous calls for collective activism, unionisation, and 'counter-discourses', so seems too individualistic for what's actually being proposed. My aim, though, is to explore Berg and Seeber's moral critique of cultures of speed in higher education and to connect them with a character-based account of corruption.

Berg and Seeler consistently invoke the moral critique of a culture of speed. 'Slowing down is a matter of ethical import', they announce, since '[t]o drive oneself as if one were a machine should be recognised as a form of self-harm', and 'being machine-like will hardly generate compassion for others' (Berg \& Seeber, 2016, p. 58). Moreover, this concern is at times articulated using a vocabulary of vices: internalising the imperatives of the culture of speed drives us to 'hate students' - who 'eat up' and make 'demands' on our time - and we become 'jealous, impatient, and rushed', no longer 'allowing room for others and otherness' (Berg \& Seeber, 2016, pp. 58-59). Nor are such connections between speed and vices unique to them, since they quote others, like William Deresiewicz, for whom academic labourers, like every other part of the American workforce, are becoming ever-more 'cowed, harried, docile, disempowered', an injustice disguised by 'the stereotype of the lazy academic', one as absurd as it is politically useful (quoted in Berg and Seeber (2016), p. 3).

A difficulty with these remarks is that the reference to those vices may be idiomatic, reflecting the available critical resources of our language, not any substantive commitment to anything like a conception of moral and intellectual character. Not everyone who talks about vices does so in the conceptually heavyweight sense in which a philosopher might use those terms. 
Elsewhere, in fact, Berg and Seeber talk of a shared need to recall 'the values of density, complexity, and ideas which resist fast consumption' (Berg \& Seeber, 2016, p. 66). Arguably, the pursuit of such values requires, among other things, virtues that enable us to be responsive to those values - broadmindedness, intellectual carefulness, reflectiveness. The teacher or researcher comfortable with complexity is unlikely to be someone prone to want to rush through the processes of enquiry to impatiently get onto the next big project. ${ }^{2}$ Sometimes, we can rush and still do a task well enough, but not with many of those tasks integral to the sorts of complex enquiries typical of higher education.

One question, then, is which sorts of vices might be promoted by a culture of speed? What sorts of dispositions or character traits would mark out a person who has internalised thoroughly the attitudes and imperatives of a culture of speed? No doubt many, although it seems to me there is a certain discernible cluster of what one might call accelerative vices, that can include aggressiveness, dominativeness, impatience, and sloppiness. Each is a kind of failure of awareness, discernment, judgment, or sensibility and they show themselves in failures to comport oneself in ways appropriately responsive to the values or goals integral to the epistemic and interpersonal practices proper to higher education. Some accelerative vices tend to result in destructive (or self-destructive) behaviours, such as a willingness to exploit the wellbeing of other people to ensure more rapid production. Pushing people beyond healthy or sustainable limits until they collapse or crash or break down is only the most obvious form of exploitativeness. Others are failings of interest and comprehension, like the insensibility and superficiality characteristic of those keen to rush past the subtleties and nuances of things - who choose rapidity and 'pace' over steadiness and depth, and who choose to remain on the surface of things, because diving into the depths takes more time than they will spare.

A deeper worry about the accelerative vices is that they can spread beyond specific activities and practices and start to corrupt one's entire stance towards academic work and communities and their ideals. In extreme cases, 'disciples of speed' will start to experience all of their commitments and interactions as a frenzy of demands and possibilities for ever-more activities and outputs. Without any brakes, this attitude can start to lend to their life as a whole a grim mood marked by insatiability, relentlessness, and remorselessness. Such corrupting reinforcement is more likely if two sorts of conditions obtain. First, if those vices are interpersonally reinforced, for instance, if colleagues come to be experienced through relationships of competitiveness and onerous demands, rather than mutual concern and care (see Johnson, 2019). Second, corruption is more likely if the accelerative vices are fuelled by cultural pressures and imperatives geared towards ever-increasing productivity or probative imperatives to perform, impress, outdo, and 'wow' others - to go further, faster, and achieve ever more awards, citations, outputs, and 'markers of esteem'.

I think that Berg and Seeber are sympathetic to this idea that internalisation of the culture of speed can, among its many sins, tend to systematically damage or corrupt the moral and intellectual character of teachers and researchers higher education. Certainly, this idea is consistent with their warning that 'the conditions for academic research are being changed in very real ways' (Berg \& Seeber, 2016, p. 63). But two aspects of those changing conditions matter for those who want to make corruptionist criticisms: first, the erosion or weakening of social and interpersonal conditions receptive to the cultivation and exercise of virtues, and, second, the establishment and entrenchment of conditions that facilitate the development and exercise of vices. In a sense, these might converge in a deeper problem. A culture of speed incorporates and impose a normative conception of the ideal academic, a fast and efficient worker who exemplifies 'ideals of mastery, self-sufficient individualism, and rationalism' (Berg \& Seeber, 2016, p. 12). However, my corruptionist analysis as it stands neither entails nor requires that specific claim about those values, although I share familiar worries about their gendered character and distorted characterisation of our epistemic and social agency. Few of us are such autonomously masterful beings. 
I now want to suggest that moral critique of the culture of speed should also include awareness of the ways that certain virtues get crowded out, marginalised, ignored or simply left behind. This is a different sort of corruption, involving the failure to cultivate or exercise virtues and excellences, rather than the development of vices and failings. Cultures of speed can be corrupting in the sense that they starve and repress certain virtues, and here I draw out the characterological implications of Áine Mahon's complaint that cultures of speed can enforce 'a privileging of the rapid and the eager' (Mahon, 2021, p. 3). One aspect of that is the privileging of forms of character and styles of thought and action characterised by rapidity, speed, and acceleration - from the hasty rush to form judgements, to an insouciance about moral and epistemic standards that would slow one down, to the aggressive desire to force others to up their pace to serve one's own ends. Such a culture is going to be hostile to the cultivation and exercise of virtues and habits that are Slower - ones like conscientiousness, diffidence, and reticence, which are anyway neglected in contemporary philosophical virtue theory (see Smith, 2006). What will emerge, in the next section, is that cultures of speed can force out these Slower virtues by spoiling the delicate, vital, mutually-facilitating connections between individual virtue, other-regarding concern for others, and the experience of time.

\section{Speed and selfishness}

Much of higher education life involves actions and practices are collaborative in the sense of their involving other people - our students, most obviously, and colleagues within our own department and institution and beyond. Collaboration, though, could be understood in two ways: the capacity to work well with others, or, more expansively, the disposition to help and support other people. I'd describe my colleagues as collaborative if we work together in ways that are efficient, professional, and respectful. Some of those colleagues, though, also seem collaborative in the further sense: they feel it is important to help others develop, advance their projects, and cope with any challenges or dangers they face. One's ability and willingness to offer such help will partly be shaped by our character traits and dispositions, a thought that sustains Ryan Byerly's recent account of a distinctive set of what he calls 'other-regarding virtues', those characterised by the specific motivating concern for others' wellbeing. In the case of other-regarding epistemic virtues, a unifying feature is what Byerly calls epistemic benevolence, defined as 'a refined motivation to promote others' epistemic goods as such for its own sake' (Byerly, 2020, ch. 4, p. 1). In a sense, it is the interpersonal analogue of the love of knowledge which, for Linda Zagzebski, unifies all the epistemic virtues: epistemic benevolence is the love of knowers, that is, a deep caring or concern for the epistemic wellbeing of others that manifests itself in acts of other-regarding virtue. Such a person might, for instance, try to promote or enhance the epistemic goods of others by providing inspiration and assistance, constructively and genially participating in their epistemic projects, or trying to help shape their development as an enquirer in ways that honour their distinctive interests and sensibilities - and so on.

Put in those terms, it is easy to see the importance of epistemic benevolence within higher education, perhaps as a professional virtue of educators. Teaching, for instance, done well, aims at cultivating the confidence, abilities, and understanding of students, as do other activities like pastoral caring and taking genuine pleasure in their development and success. In the case of colleagues, one might show active interest in their work, offer comments and ideas, and in other ways contribute to their research projects. Such acts of other-regarding epistemic virtue must, of course, be structurally facilitated by effective and equitable sorts of institutional and disciplinary scaffolding - like journal peer review systems. It should also be noted that acts of epistemic benevolence often multiply motivated, too, by, among other things, love of one's subject, care for students, a sense of duty, institutional and contractual obligations, and a desire to impress or gain credit with colleagues. It is for this reason that Byerly emphasises that the 
ideal of epistemic benevolence is that of a refined motivation, a term that suggests disciplined processes of purification, of altering something until one gets it 'just right'.

A crucial material precondition for cultivation and exercise of epistemic benevolence and its associated virtues is the availability of sufficient amounts of flexibly structured time for performance of relevant acts. Philosophical virtue theorists do not always attend to the material preconditions of virtue, such as time and energy and being well-fed, but they are as important to virtuous agency as ethical values and epistemic motivations. Consider some of obvious sorts of epistemically benevolent academic actions: commenting on a colleague's manuscript; sitting down to carefully select readings for a student struggling with a specific topic; writing careful and detailed comments for a referee report; acting as a mentor to an anxious junior colleague; accepting the invitation of a colleague from another department to attend their talk, which touches on some points of philosophy on which they'd appreciate guidance. Among other things, all these actions require time, whose absence or availability can therefore determine our ability and willingness to perform said actions. Moreover, with these sorts of actions, the more time one can give, the better these can be done, up to a point. Referee reports can be a short paragraph with brusque remarks or several paragraphs of detailed comments on structure, argument, and scholarship that take an hour to prepare.

An obvious problem of life in modern higher education, indeed of life at large, is that too many of us are, to use a recent neologism, 'time-poor'. As with money, some are poorer than others and there are the usual patterns of inequalities. Moreover, there are the usual inadequacies of most 'workload models', like underestimating the demands of certain roles, and failure to include certain kinds of work, like exam scrutiny meetings or reviewing grant applications. When people have more and more to do in less and less time, there are severe choices to make - what to drop, when to cut corners, when to lower one's standards, and so on. All of this, of course, contributes to a working culture that is hostile to proper exercise of the other-regarding virtues, since attentively caring for others is one thing that often takes a lot of time. Granted, a brief chat or a short, brisk referee report can be helpful, and there is such a thing as excessive and protracted acts of benevolence (a two-sentence referee report may be too little, a twenty-page report too much). One should not race from embrace of Fast to an equally zealous embrace of Slow, since the ideal is in knowing how fast to go and being free to do so (see Smith, 2019).

I want to focus, though, on the ways that cultures of speed can obstruct the exercise of other-regarding virtues by changing, for the worst, our experience of time. Berg and Seeber note how modern concepts like 'time poverty' and 'time crunch' are, in academic contexts, 'detrimental to intellectual work, interfering with our ability to think critically and creatively' (Berg \& Seeber, 2016, p. 17). One either fails to perform certain acts, or one has less time to do them in the appropriately timely ways to appropriately high standards. Alternatively, acts are never performed, or done too late, or done to too a poor standard, until, over time, one starts to strategically limit the range of one's commitments. Although often essential, the consequence is a systematic reduction of one's structured commitments to advance the epistemic wellbeing of others - like withdrawing from mentorship schemes, refusing journal referee requests, refusing supervision requests from students, and so on.

A lack of time, though, is only one way that cultures of speed can militate against the exercise of other-regarding virtues. Some further, deeper aspects include the internalisation of new imperatives which affect one's experience of competing demands. If one has a few hours spare, the structural pressures are to 'spend' it on certain actions esteemed by values internal to the culture of speed. We can distinguish two general sorts of competition. First, competing activities: the sense that, whatever one's goals and values, there are other things one should be doing, like writing articles for high-impact journals of writing grants with tiny chances of success rather than, say, writing comments on a colleagues' work. Second, there are competing values: one's time should be spent on activities that honour the values built into modern higher education 
- self-advancement, 'impact', prestige, productivity - which, even if not endorsed, still exercise significant normative power. Alongside these two sorts of competition, we can also add the problem that so much time is wasted, on pointless tasks, needlessly complex forms, superfluous meetings, and over-elaborate procedures.

I think that these are important ways that cultures of speed militate against the exercise of other-regarding virtues in higher educational environments. Certainly, they are familiar to most academics, at least if my university is typical. But they are, in a sense, too superficial as they stand: what they describe are structural and institutional problems with the availability and distribution of time construed as a resource - as something to be shared, spent, lost, or invested (see Lakoff and Johnson (1980), pp. 66-67ff). Alongside these institutional changes is the distortion to our first-person experience of time that occurs when we internalise the values and imperatives of a culture of speed - the temporal phenomenology of Berg and Seeber's 'disciple of speed'.

The distortions to our experience of time are nicely captured by Berg and Seeler's remark that academics are increasingly 'caught between two temporalities: corporate time and the time conducive for academic work' (Berg \& Seeber, 2016, p. 25). Here they draw on research by Oili-Helena Ylijoki and Hans Māntalyā, who criticise time-auditing for its insensitivity to 'the internal rhythms of the work itself', a failure to appreciate that 'true research takes - and must be allowed to take - all the time it needs' (Ylijoki \& Mäntylä, 2003, pp. 74, 63). This idea is, as Berg and Seeber note, 'extraordinarily radical in the current climate' (Berg \& Seeber, 2016, p. 26). Corporate time, on this view, works according to time scales and expectations of speed and pace that are invariably disconsonant with the actual temporal needs of research practices; think, here, of familiar temporally-toned talk of the process of research needing time to play with ideas, to put a draft paper away then later coming back to it, letting ideas stew, and so on.

I worry that the internalisation of a psychology of speed has, among its baleful effects, an increasingly extreme distortion of our experience of time that erodes our willingness and ability to exercise other-regarding virtues. When time is rare, precious, and constantly at risk of being taken away, one will find it ever harder to create and protect the necessary expanses of uninterrupted time needed for carefulness, thoughtfulness, imaginativeness, and spontaneity. Moreover, one can start to resent the ways other people place demands on our time; granted, some people do this unfairly, although our willingness to see a time-demand as an imposition will increase as our temporalities become corrupted.

A very severe sort of corruption occurs when our internalised psychology of speed starts to erode our capacity for a sort of humility, one taking the form of a respect for the integrity of research work - for its own rhythms and own pace, things that cannot be accelerated without risk of spoiling them. (Consider the motto of Slow Science Manifesto: 'Bear with us, while we think'). A disciple of speed, one fears, starts to become averse to spending time on other-regarding actions that are not institutionally esteemed and rewarded; worse, though, they cease being capable of experiencing time in certain positive ways - as available, open, expansive in ways suited to unhurried, open-ended exploration of ideas and possibilities of understanding and interpretation. A disciple of speed also ceases to be responsive to the rhythms of thought, seeing slow progress not as a sign of encountering depth or difficulty, but as an epistemic tardiness that needs kicking up a gear. What goes slow must be forcibly accelerated, even if that comes at serious cost of the integrity of those explorations.

At its heart, these corrupted temporalities will entail a certain failure of truthfulness as well as a failure of humility. Although difficult to express, my thought is that our research practices should be truthful, that is, informed by an accurate and sincere appreciation of the rhythms and realities of complex, delicate processes of thought and understanding. What connects humility and truthfulness is, perhaps, a sense of fidelity: the wise acceptance that certain things and processes cannot be wilfully transformed to make them conform to our demands and 
imperatives without doing severe violence to their own integrity (Cooper, 2008, p. 81). As Mahon explains, 'our relationship with time is defined in a much more complex sense by different bodily and worldly rhythms; and by rethinking these rhythms, we can actually rethink our relationship with education altogether' (Mahon, 2021, pp. 9-10).

A culture of speed, if internalised, can and perhaps almost certainly will distort our experience of time in ways that corrupts those in its thrall by dampening their willingness and ability to perform the acts expressive of the other-regarding virtues. In our rush to perform, impress, or just keep up, what we lose is what Berg and Seeber calls 'the timeless time that fosters creativity, original thinking, and, as a bonus apparently, joy' (Berg \& Seeber, 2016, p. 27).

\section{Pace and progress}

I have argued that Berg and Seeler are right that culture of speed, driven by the values of efficiency, and productivity, is at odds with 'an understanding of the ethical dimension of time because it forecloses potential ways of being and knowing' (Berg \& Seeber, 2016, p. 58). We are increasingly subjected to a culture of speed that, when institutionally manifested and if individually internalised, deprives us of the time, energy, and freedom to happily exercise an important range of virtues integral to higher educational practice.

Certainly, higher educational cultures of speed are very distant from alternative and, for some, more attractive visions of education. Oakeshott, famously, characterised education in terms of edifying conversation, a civilized and civilizing process of 'initiation' into 'an inheritance of human achievements of understanding and belief' (Oakeshott, 1989, p. 59). The metaphor of a conversation brings with it a certain 'temporality', a sense of how to engage with others in a proper spirit of pace and movement. Such conversations should be marked by 'genial flow', where discussion 'wanders, responsive to every breeze', in neither 'slow sententiousness' nor an 'impatient cascade of words' (Oakeshott 2004, pp. 189, 190, 189). Whatever one thinks of an ideal of edifying educational conversation, it is increasingly hard to realise in modern higher educational environments dominated by culture of speed. A proof of this are the appeals, including those quoted by Berg and Seeber, for an 'ethics of time' and the insistences that time is 'our most pressing infrastructural (and personal and political) need' (quoted in Berg and Seeber (2016), pp. 59, 73).

A critic might respond that such concerns are all very well, but they run into two very significant obstacles. The first is that there really is no clear alternative to participation in the modern academic cultures of speed, however much one laments being caught up in them. An appeal for Slow scholarship and recitation of the moral, psychological, and other concerns are all well and good. In practice, though, Fast is, for now, here to stay - to exploit a further aspect of the metaphor, even if we slammed on the brakes, there is so much energy and momentum in the system that it would continue racing ahead for a long time before it comes to a stop. It may well be possible for academics to try and publish less, stop rushing from one project to another, and so on - but then the whole academic system of reputation and evaluation would come into play. If speed is as entrenched as critics fear, then those who do slow down either lose out or get left behind. Some might not mind that, of course. Others will, though, meaning they are in the situation of Alice when confronted with the Red Queen of having to run as fast as they can just to stay where they are. Indeed, for many academics - precarious and anxious - the very idea of their having the freedom to choose to slow down may met with a scoff.

A second obstacle to criticisms of cultures of speed is that many academics may well endorse them. Clearly enough, some academics have the energy and resources to go fast and keep accelerating - they keep up their peak position in the academic bleep test, going faster even as the pace increases. Some are naturally energetic, some have powerful resources, and others 
will have the whole variety of epistemic and professional appetites and drives. It would be a mistake to think that everyone is receptive to the ideal of 'going slow'. Granted, there are fetishists of speed, like Marinetti, but that is one particular extreme valorisation of speed. Consistent with the metaphor, there are slower and faster styles of life and thought and what we should distinguish are those whose speed owes to their motivations and energy and those who are being constantly forced to accelerate despite their desires and against their sense of self-preservation.

One response to these criticisms is to introduce an idea that is strangely lacking in the literature on speed and slowness: the concept of pace. Recall Honoré's remark that he wasn't trying to condemn speed and praise slow tout court and his remark - which may sound banal - that what we need is 'balance: instead of doing everything faster, do everything at the right speed. Sometimes fast. Sometimes slow. Sometimes somewhere in between (Honoré, 2005, p. 274). Problems only arise when one cannot accelerate or slow down when necessary or when we cannot maintain a proper rhythm of acceleration and deceleration that fits with our needs and concerns as they change over time. What is needed, then, is an attainment musicians call tempo giusto - the ability to achieve an ideal tempo, which involves a set of sensitivities and skills and a constant responsiveness to the pace or rhythm of life. 'Sometimes fast. Sometimes slow'. A human life, like a piece of music, cannot be properly performed at a single speed. Perhaps what our entrenched cultures of speed obstruct is a capacity for tempo giusto, the cultivated ability to think and live according to a proper sense of pace or rhythm (Kidd, 2021).

The concept of a proper pace may offer a richer way to think about the problems of a culture of speed and the potential problems of a future culture of slow. What is being eroded is a capacity for a more authentic sort of self-guided epistemic and professional conduct - the ability to properly pace one's work in ways that are consistent with high-quality work, mental and physical health, and the moral requirements of academic practice, like conscientiousness and other virtues. The concern of advocates of slowness is that, right now, things are going too far in the direction of speed and acceleration. The zeal for speed, unless resisted or overcome, will continue to erode the conditions needed for cultivation of rich and mutually sustaining interpersonal relationships characterised by trust, spontaneity, and deep mutual acquaintance. We often know we are going too fast - rushing through thoughts that ought to be slowly explored; hurrying though what should be savoured - but the culture as it is now is hostile to the possibility of slowing down. In that way, tempo giusto is structurally excluded: the pace is defined relative to the pressures and imperatives of an accelerated system, whose consequence is the weakening of the virtues we need to properly pace ourselves. This is the deep worry driving the concerns about moral and intellectual corruption of moral and intellectual raised by Berg and Seeber. if I am right, their talk of moral criticism of cultures of speed includes a concern about the destructive effects on the moral and intellectual character of academics. Accelerative vices come to displace those Slower virtues that are integral to certain kinds of academic practice, especially those which require of a degree and freedom of time increasingly unavailable. 'Disciples of speed' are prone to patterns of individual and collective behaviour characterised by traits like aggressiveness, exploitativeness, insensibility, rapacity, and superficiality. If so, that explains talk of corruption of scholars and their mission: a good colleague, teacher, or custodian needs to be able to manifest the Slower virtues of conscientiousness, fairmindedness, and thoughtfulness. Ultimately, they must be able to run their affairs with tempo giusto - at an ideal tempo, or something much closer to it than what is currently possible. Slowness and speed must therefore be accompanied by the concepts of rhythm and pace. Quite what an academic culture receptive to these sorts of temporalities is going to be like is a task for another time (see Chubb et al., forthcoming). For now, I hope to have shown that conceptualising it will require a due appreciation of the moral dimensions of slowness and speed and something like the concept of pace. The ultimate goal is that academic cultures will enable the sorts of virtues and temporalities that might fulfil Mahon's hope: 'if we can exist together in 
these less instrumentalist and less harried modes then we might have world enough and time for education and for each other' (Mahon, 2021, p. 10).

\section{Notes}

1. Actually, earlier writers had made similar calls for slower styles of life, from Bertrand Russell's essay In Praise of Idleness to the 14th century Japanese monk Yoshida Kenkō's Essays in Idleness.

2. interestingly, Locke criticised a vice he called 'Haste', one common, he felt, among undisciplined scholars: 'The eagerness and strong bent of the mind after knowledge, if not warily regulated, is often a hindrance to it. It still presses into further discoveries and new objects and catches at the variety of knowledge, and therefore often stays not long enough on what is before it to look into it as it should, for haste to pursue what is yet out of sight' (Locke, 1996, p. 201, §25).

\section{Acknowledgements}

I am grateful to the editor for the invitation to contribute and to two anonymous referees for their encouragement and helpful critical suggestions. Some of the ideas were also worked out in discussions with Ryan Byerly, David E. Cooper, Ainé Mahon, Richard Smith, John Tillson, and an audience at the Centre for Education and Policy Analysis at Liverpool Hope University. Research for this paper was supported by a fellowship as part of the Epistemic Responsibilities of the University project at the Vrije Univeristeit Amsterdam, funded by the John Templeton Foundation.

\section{Funding}

This work was written as part of the project The Epistemic Responsibilities of the University, funded by the Templeton World Charity Foundation.

\section{Notes on contributor}

Ian James Kidd is a lecturer in philosophy at the University of Nottingham. His research interests include epistemic virtues and vices and the philosophy of education. His website is www.ianjameskidd.weebly.com.

\section{References}

Arthur, J., Kristjánsson, K., \& Harrison, T. (2016). Teaching character and virtue in schools. Routledge.

Baehr, J. (Ed.). (2015). Intellectual virtues and education: Essays in applied virtue epistemology. Routledge.

Battaly, H. (2013). Detecting epistemic vice in higher education policy: Epistemic insensibility in the seven solutions and the REF. Journal of Philosophy of Education, 47(2), 263-280. https://doi.org/10.1111/1467-9752.12024

Berg, M., \& Seeber, B. (2016). The slow professor: Challenging the culture of speed in the academy. University of Toronto Press.

Byerly, R. T. (2020). Intellectual Dependability: A Virtue Theory of the Epistemic and Educational Ideal. Routledge.

Chubb, I. J., Kidd, J., \& Forstenzer, J. (forthcoming). Epistemic corruption and the research impact agenda. In Theory and Research in Education.

Collini, S. (2012). What are universities for? Penguin.

Cooper, D. E. (2008). Teaching and truthfulness. Studies in Philosophy and Education, 27(2-3), 79-87. https://doi. org/10.1007/s11217-007-9091-x

Honoré, C. (2005). Praise of slowness: Challenging the cult of speed. HarperCollins.

Johnson, C. (2019). Teaching as epistemic care. In B. Sherman \& S. Goguen (Eds.), Overcoming epistemic injustice: Social and psychological perspectives (pp. 255-268). Rowman and Littlefield.

Kidd, I. J. (2019). Epistemic corruption and education. Episteme, 16(2), 220-235. https://doi.org/10.1017/epi.2018.3

Kidd, I. J. (2020). Epistemic corruption and social oppression. In I. J. Kidd, H. Battaly \& Q. Cassam (Eds.), Vice epistemology: Theory and practice (pp. 69-87), co-edited. Routledge.

Kidd, I. J. (2021, September 11). Going slow. Daily Philosophy.

Kidd, I. J. (2022). Character, corruption, and 'cultures of speed' in the academy. In Á. Mahon (Ed.), The promise of the university: Reclaiming humanity, humility, and hope. Springer (in press).

Lakoff, G., \& Johnson, M. (1980). Metaphors we live by. Chicago University Press. 
Locke, J. (1996). Some thoughts concerning education and of the conduct of the understanding (R. W. Grant \& N. Tarcov, Eds.). Hackett.

Mahon, A. (2021). Towards a higher education: Contemplation, compassion, and the ethics of slowing down. Educational Philosophy and Theory, 53(5), 448-458. https://doi.org/10.1080/00131857.2019.1683826

Nussbaum, M. (2010). Not for profit: Why democracy needs the humanities. Princeton University Press.

Oakeshott, M. (1971). Education: The engagement and its frustration. Journal of Philosophy of Education, 5(1), 43-76. https://doi.org/10.1111/j.1467-9752.1971.tb00448.x

Oakeshott, M. (1989). The voice of liberal learning. In T. Fuller (Ed.), Michael Oakeshott on education. Yale University Press.

Oakeshott, M. (2004). What is history? And other essays (Ed. L. O'Sullivan). Imprint Academic.

Petrini, C. (2004). Slow food: The case for taste. Columbia University Press.

Sandel, M. (2012). What money can't buy: The moral limits of markets. Penguin.

Shklar, J. (1984). Ordinary vices. The Belknap Press of Harvard University Press.

Smith, R. (2006). On diffidence: The moral psychology of self-belief. Journal of Philosophy of Education, 40(1), 51-62. https://doi.org/10.1111/j.1467-9752.2006.00498.x

Smith, R. (2019). Education, fast and slow. Philosophy of Education Society of Great Britain Annual Conference (pp. 29-31). March.

Taylor, G. (2006). Deadly vices. Oxford University Press.

Ylijoki, O.-H., \& Mäntylä, H. (2003). Conflicting time perspectives in academic work. Time \& Society, 12(1), 55-78. https://doi.org/10.1177/0961463X03012001364 